\title{
Only the endophyll-Rauber's sickle complex and not cells derived from the caudal marginal zone induce a primitive streak in the upper layer of avian blastoderms
}

\author{
Marc Callebaut*, Emmy Van Nueten, Luc Van Nassauw, \\ Hilde Bortier, Fernand Harrisson
}

\begin{abstract}
RUCA, UA, Laboratory of Human Anatomy \& Embryology, 171 Groenenborgerlaan, B-2020 Antwerp, Belgium
\end{abstract}

(Received 16 September 1997; accepted 10 June 1998)

\begin{abstract}
From unincubated quail blastoderms, we have excised, caudal marginal zones (caudally from Rauber's sickle), upper layer fragments covering Rauber's sickle or Rauber's sickle fragments alone (as controls), and placed them on the ventral side of the cranial quadrant of unincubated chicken blastoderms. Also, quail Rauber's sickle fragments, all or not associated with quail endophyll, were placed on the ventral side of isolated central upper layer discs of prestreak chicken blastoderms from which the deep layer was previously removed. Only the Rauber's sickle-derived cells (sickle endoblast cells), placed on unincubated or shortly incubated blastoderms induce, after culture, a primitive streak (PS) and a normal embryo. This indicates, together with previous experimental evidence, that even in the presence of endophyll, neither the deep part of the caudal marginal zone nor the upper layer above it can induce a primitive streak. This experimental study affords further evidence that the function of the avian Rauber's sickle is homologous to the function (mesoderm induction) of the vegetal dorsalizing cells (Nieuwkoop centre) in amphibian blastulas. (O) Inra/Elsevier, Paris
\end{abstract}

avian blastoderm / Rauber's sickle / caudal marginal zone / endophyll / gastrulation / quailchicken chimera / primitive streak

Résumé - Seul le complexe entophylle-croissant de Rauber et non les cellules provenant de la zone marginale caudale est capable d'induire une ligne primitive dans l'ectophylle du blastoderme d'oiseaux. Chez des blastodermes non-incubés de caille, nous avons prélevé des zones marginales caudales (localisées derrière le croissant de Rauber), des fragments d'ectophylle couvrant le croissant de Rauber et des fragments de croissant de Rauber (comme témoins). Ensuite, ces différentes structures ont été placées sur la face ventrale du quart cranial d'un blastoderme non-incubé de pou-

\footnotetext{
* Correspondence and reprints
}

E-mail: macal@ruca.ua.ac.be 
let. Des fragments du croissant de Rauber de caille, associés ou non à de l'entophylle, ont également été placés sur la face ventrale de l'ectophylle de blastodermes de poulet (dépourvu de couche profonde) incubés jusqu' au stade avant l'apparition de la ligne primitive. Après culture, seuls les fragments du croissant de Rauber associés à l'entophylle ont induit une ligne primitive dans l'ectophylle de blastodermes non-incubés de poulet. Ce résultat indique, ensemble avec nos resultats d'expériences précédentes que, même en présence d'entophylle, ni la partie profonde de la zone marginale caudale, ni l'ectophylle situé au-dessus, peuvent induire une ligne primitive dans l'ectophylle de poulet. Le croissant de Rauber chez les oiseaux semble être homologue au centre de Nieuwkoop chez les amphibiens. $\odot$ Inra/Elsevier, Paris

blastoderme d'oiseau / croissant de Rauber / zone marginale caudale / entophylle / gastrulation / chimère caille-poulet / ligne primitive

\section{INTRODUCTION}

Recent studies [5-10] yielded new data about the structures and developmental events in avian intrauterine germs after bilateral symmetrization and in unincubated eggs. To describe them, we have adopted an unequivocal terminology of the involved structures. The different components of the deep layer of an unincubated quail blastoderm and terminology used are represented in figure 1.

Rauber [34] and later Koller [27] were the first to describe a sickle (often visible from the exterior) in the future caudal part of the deep layer of unincubated avian blastoderms. Rauber [34] already considered that this structure was at the origin of a forward migration of cells, so that a progressively enlarging sheet of tissue expands in a caudocephalic direction below the upper layer (UL) of the area pellucida. Since the experimental work of Waddington [43] demonstrating the inductive role of the endoblast (deep layer) on the upper layer in avian blastoderms, numerous investigations have been performed on the same topic. As far as we are aware, Vakaet $[40,41]$ was the first to make a radical distinction between endophyll (early caudocentral deep layer component which can not be completely separated from the UL) and the other endoblastic structures (figure 1). As shown by Vakaet $[40,42]$ in the chicken and by Callebaut [3,
4] in the quail, the endophyll is localized in the cranial prolongation of the sickle of Rauber [34] from which the Anlage already forms in utero after symmetrization [5, 7]. The caudo-cephalic sliding movement of the endophyll-sickle endoblast complex below the upper layer during early incubation, has been demonstrated by Vakaet [ 40 , 42] using labelling with carbon marks. Recent studies $[9,10]$ indicate that Rauber's sickle is the early gastrulation organizer in the avian blastoderm. As far as we know we were the first to clearly isolate and transplant Rauber's sickle fragments (using quail blastoderms) without including other deep or upper layer cells. Izpisua-Belmonte et al. [23] also tried it but without success. In combination with endophyll, Rauber's sickle induces a normal embryo in the UL. Both structures belong to the so-called extraembryonic part of the blastoderm. Indeed in all our transplantation studies during which part of a quail Rauber's sickle or quail endophyll was placed on an unincubated chicken blastoderm, we never found after incubation quail cells in the embryo proper (only composed of chicken cells). The question in the present study is to find out if structures other than the endophyll-Rauber's sickle complex can induce an embryo in the UL, and whether Rauber's sickle fragments still induce a normal embryo in UL central disks of older blastoderms. Rauber's sickle cells seem to be homologous to the 


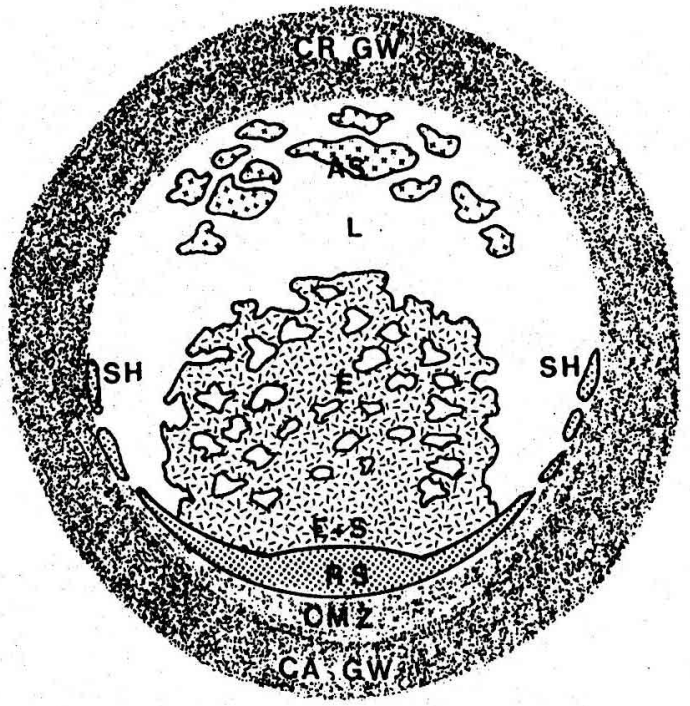

Figure 1. Schematic representation of the components of the unincubated quail blastoderm seen from below after removal of the subgerminal ooplasm, ready for in vitro culture; CRGW: cranial germ wall; AS: anti-sickle region; L: lacune in the deep layer; E: incomplete endophyll sheet; $E+S$ : region of the deep layer where sickle endoblast derived from the Rauber's sickle (RS) meets the endophyll; $\mathrm{SH}$ : fragmentary sickle horns; CMZ: caudal marginal zone, more or less transparent; CA GW: caudal germ wall. vegetal dorsalizing cells described by Nieuwkoop [31, 32] in amphibian blastulas [12]. The anti-sickle region was first described by Callebaut [5] in gravitationally oriented quail germs. In this anti-sickle region, an irreversible disruption between the future cranial part of the germ and the underlying subgerminal ooplasm takes place at the moment of bilateral symmetrization [6-8]. The anti-sickle region is composed only of an upper layer below which some disrupted loose yolk masses or cells are seen. No endophyll is morphologically or potentially present in the anti-sickle region $[10$, 15]. We demonstrated that none of the three elementary tissues (Rauber's sickle, endophyll and upper layer: Callebaut and Van Nueten [11]) of the avian unincubated blastoderm present at that moment an irreversible functional polarity and that normal gastrulation and neurulation can take place even in the total absence of the marginal zone [12]. The same study indicated that endophyll directs the movement of sickle material to form sickle endoblast $[9,10]$, which in turn induces a primitive streak in the upper layer. Until now, the earliest morphogenetic movements occurring at the onset of incubation of avian germs were not well known. Particularly, the distinction and boundaries between the first two deep layer components (endophyll and sickle endoblast) is (without marking) difficult or impossible to make. In a recent study [12] using isotopic quail-chicken exchange experiments, we demonstrated that cells localized in the caudal marginal zone (i.e. caudally and laterally from Rauber's sickle) remain in situ during incubation and do not participate in gastrulation. Indeed, we observed morphogenetic movements of gastrulation and neurulation only in the area centralis of the area pellucida and never in the marginal zone. These observations are in contradiction to the hypothesis of Spratt and Haas [38], of Eyal-Giladi [17] and of Eyal-Giladi et al. [20,21], that the caudal marginal zone (even without Rauber's sickle) plays an important role during gastrulation and that its cells will ingress and form different mesodermal components [24]. Therefore in the present study, we have excised from unincubated quail blastoderms caudal marginal zones (peripheral to Rauber's sickle) upper layer fragments covering Rauber's sickle or Rauber's sickle fragments alone (for comparison and as controls), and placed them on the deep side of unincubated blas- 
toderms followed by culture. The results indicate that only Rauber's sickle cells (sickle endoblast) interacting with endophyll induce a primitive streak in the upper layer.

\section{MATERIAL AND METHODS}

We used unincubated chicken and unincubated quail blastoderms, presenting a sickle of Rauber [34], from eggs stored at $15-20^{\circ} \mathrm{C}$ for $1-2$ days. Also prestreak (stage XIII [18]) chicken blastoderms were used.

\subsection{Histological observations of the germ disc of the unincubated quail egg}

In order to clarify contradictory opinions [21, $39,42]$ about the morphology and some topographical relationships between the different components of the avian unincubated blastoderm and its subgerminal and perigerminal ooplasm (forming together the germ disc), we have studied some mediosagittal sections under the microscope. These were obtained by rinsing the quail egg yolk balls in Ringer, followed by fixation in toto with the blastoderm left in situ on the egg yolk ball. After embedding and sectioning, the sections were stained with iron hematoxylin and eosin.

\subsection{Transplantation study}

After opening of the chicken eggs and removal of the egg white, the egg yolk balls were placed in Ringer's solution. The vitelline membrane was sectioned all around the equator of the yolk ball and removed from the yolk by a slow movement in the direction of $/$ and bending $180^{\circ}$ over the germ. In this manner, the chicken blastoderm, still adhering to the vitelline membrane and the underlying subgerminal ooplasm could usually be separated from the yolk. By contrast, in the quail, this procedure is only exceptionally successful since the unincubated quail blastoderm almost always detaches from the vitelline membrane. Therefore, to isolate unincubated quail blastoderms, the germ and surrounding yolk must first be excised from the egg yolk ball. Subsequently, the yolk, the nucleus of Pander and the subgerminal ooplasm were progressively removed, in order to expose the deep side of the blastoderm. From some unincubated quail blastoderms, the caudal marginal zone just behind Rauber's sickle was excised and placed (either with its ventral or dorsal side) on the ventral side of the cranial quadrant of an unincubated chicken blastoderm prepared for culture in vitro (figure $2 A$ ). From other unincubated quail blastoderms, Rauber's sickle was removed and the upper layer (UL) localized superficially to the middle region of the Rauber's sickle excised and also placed (either with its ventral or dorsal side) on the deep side of the cranial quadrant of an unincubated chicken blastoderm (figure $2 B$ ). For comparison Rauber's sickle fragments were also placed on the cranial quadrants of unincubated chicken blastoderms and cultured in vitro (figure $2 C$ ). Since Eyal-Giladi et al. [20,21] never did control studies with isolated Rauber's sickles or endophyll sheets (probably owing to technical difficulties) during their transplantation studies on the deep side of central UL discs (stage XIII [18]), we carried out a complementary study by placing isolated Rauber's sickle fragments (all or not associated with endophyll) on this reactor tissue. To do this, Rauber's sickle fragments (with/or without associated endophyll) from unincubated quail blastoderms were placed on the ventral side of excised central UL discs (after removal of the deep layer) of prestreak chicken blastoderms (incubated for 8-10 h: stage XIII of Eyal-Giladi and Kochav [18]) (figure 2D). The culture medium was egg white as used by New [30]. Instead of Petri dishes, the culture vessels described by Gaillard [22], on which an optical flat glass cover was sealed with hot paraffin, were used. Stereomicroscopic Polaroid photographs were taken in the same direction at the beginning, during and at the end of the culture period ( $23-26 \mathrm{~h}$ ). Fixation was performed overnight in a modified Heidenhain's fixative [35] containing $0.5 \mathrm{~g}$ sodium chloride, $2 \mathrm{~g}$ trichloracetic acid, $4 \mathrm{~mL}$ acetic acid, $20 \mathrm{~mL}$ formalin and $80 \mathrm{~mL}$ water. After 1 day of fixation, the chimeric blastoderms were placed in $70 \%$ alcohol and dehydrated in a graded series of alcohol, cleared in xylene and embedded in paraffin. Sectioning of the chimeric blastoderms occurred perpendicularly to the visible or presumed axis. The deparaffinized $8-\mu$ m-thick sections were Feulgen-stained after Demalsy and Callebaut [16]. This allowed us to distinguish chicken from quail nuclei $[2,28,29]$. 

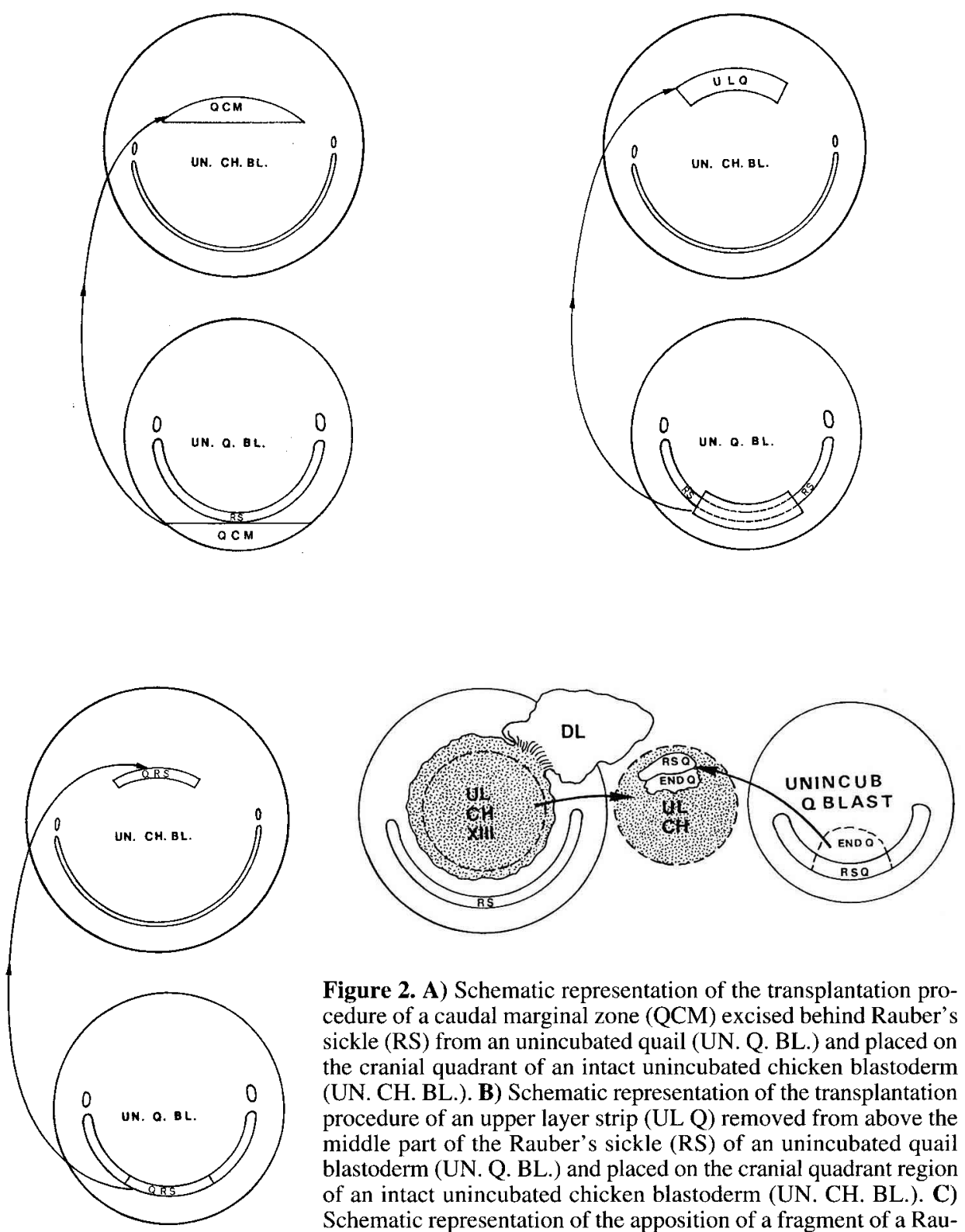

Figure 2. A) Schematic representation of the transplantation procedure of a caudal marginal zone (QCM) excised behind Rauber's sickle (RS) from an unincubated quail (UN. Q. BL.) and placed on the cranial quadrant of an intact unincubated chicken blastoderm (UN. CH. BL.). B) Schematic representation of the transplantation procedure of an upper layer strip (UL Q) removed from above the middle part of the Rauber's sickle (RS) of an unincubated quail blastoderm (UN. Q. BL.) and placed on the cranial quadrant region of an intact unincubated chicken blastoderm (UN. CH. BL.). C) Schematic representation of the apposition of a fragment of a Rauber's sickle (QRS) from an unincubated quail blastoderm (UN. Q. $\mathrm{BL}$.) on the cranial quadrant region of an unincubated chicken blastoderm (UN. CH. BL.). D) Schematic representation of the excision of a middle fragment of a Rauber's sickle (RSQ) and associated fragment of endophyll sheet (END Q) from an unincubated quail blastoderm (visible on the right) followed by apposition on the ventral side of a chicken upper layer (UL $\mathrm{CH}$ ) central disc obtained by excision from a prestreak chicken blastoderm (stage XIII [18]) after peeling off the deep layer (DL) (visible on the left). 


\section{RESULTS}

\subsection{Histological observations of the germ disc of the unincubated quail egg fixed in situ}

Figure 3 shows the caudal, the middle and the cranial part of a mediosagittal section through one and the same unincubated quail blastoderm, in situ on its subgerminal ooplasm. In the caudal region, (figure 3A), one sees that the caudal marginal zone is formed by two components: 1) an upper layer in continuity with the upper layer above Rauber's sickle and the area centralis and 2) a massive deep part (approximately $100 \mu \mathrm{m}$ thick) in intimate contact with the peripheral subgerminal ooplasm and in continuity with the more cranial Rauber's sickle. From the latter, a narrow outgrowth formed by sickle endoblast in contact with the more cranial endophyll is seen. The subgerminal cavity (forming an axilla [5]) ends abruptly against the Rauber's sickle and so often gives it a sharp delineation. In the unincubated blastoderm, a sharp separation between the caudal marginal zone and the caudal germ wall or area opaca (if already present) cannot be made. Seen from the surface of the egg yolk ball, the caudal marginal zone seems to be transparent, contrasting with the dense whitish Rauber's sickle. For this reason the caudal marginal zone is often considered as part of the area pellucida. However, by contrast to the area centralis below which the subgerminal cavity is localized, in and below the caudal marginal zone there is no cavity. In the central part of the area centralis of the blastoderm an

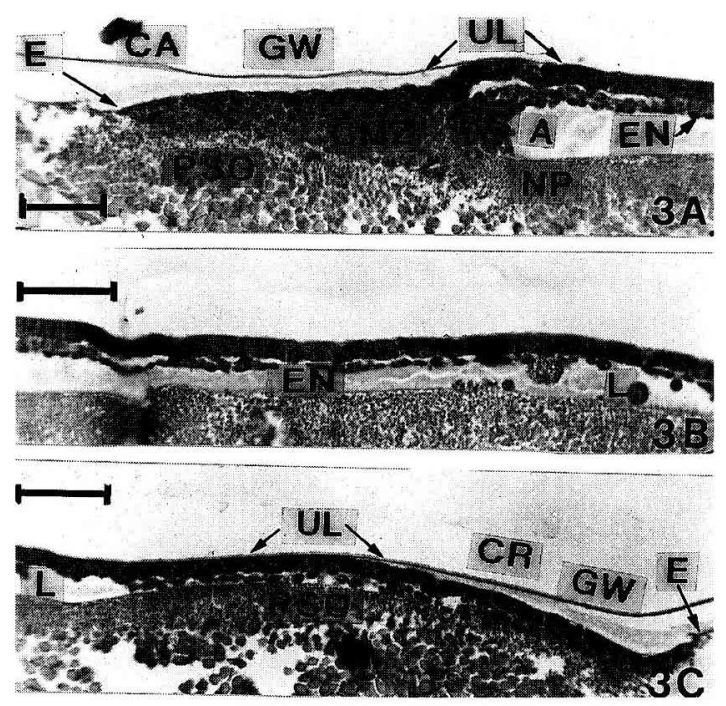

Figure 3. A) Mediosagittal section through the caudal part of an unincubated quail blastoderm fixed in situ on its egg yolk ball; RS; Rauber's sickle; CMZ: caudal marginal zone formed by a deep part behind Rauber's sickle and a superficial upper layer (UL) part; A: axilla-shaped pocket of the subgerminal space; EN: endophyll in continuity with Rauber's sickle; NP: nucleus of Pander; CA GW: small caudal germ wall in intimate contact with the caudal peripheral subgerminal ooplasm (PSO); E: arrow indicates the caudal edge of the blastoderm; iron hematoxylin and eosin staining; bar: $100 \mu \mathrm{m}$. B) Middle part of the same section as in A; EN: incomplete layer of endophyll; L: lacune in the deep layer; bar: $100 \mu \mathrm{m}$. C) Cranial part of the same section as in A and B; anti-sickle formed by loose yolk masses and cells is seen between the upper layer (UL) and the cranial peripheral subgerminal ooplasm (PSO); L: lacune; CR GW: cranial germ wall; arrow indicates the cranial edge (E) of the blastoderm. 
incomplete layer of endophyll is present below the upper layer, ending cranially as a deep layer-free area: the lacuna (figure $3 B$ ). In the more cranial part of the blastoderm (figure $3 C$ ), we see the anti-sickle region composed of an upper layer below which loose yolk masses or isolated cells are found, as the result of the loss of contact of this part of the blastoderm with the underlying ooplasm at the moment of bilateral symmetrization [6-8].

\subsection{Transplantation study}

When a caudal marginal zone fragment from an unincubated quail blastoderm was placed on the deep side of the central part of the cranial quadrant of an unincubated chicken blastoderm $(n=12)$, as represented in figure $2 A$ and seen in figure $4 A$, a progressive shrinking of the graft was observed after culture (figure $4 B$ ). In cases where the upper layer of the quail graft was facing the deep layer of the chicken blastoderm $(n=5)$, usually a large vesicle formed (figure $4 C$ ). A secundary induced primitive streak was never seen. The primary embryo developed normally, starting from the autochtonous, chicken Rauber's sickle region. During fixation, the vesicles often lose contact with the blastoderm. In sections, the vesicles appeared to be formed by quail cells. In the region of transplantation on the chicken blastoderm, not even the slightest thickening of the chicken upper layer was found, indicating that no induction has taken place. In cases where the deep layer of the marginal zone of the graft was facing the deep layer of the unincubated chicken blastoderm $(n=7)$, after culture over 1 day, a small mass was usually observed, but never a primitive streak. Sections through this mass revealed a cellular accumulation of quail cells in close contact with the chicken upper layer (figure 5). No thickening of the chicken upper layer and no PS was formed.

After placing quail upper layer (removed from above a Rauber's sickle) on the deep side of an unincubated chicken blastoderm in vitro (as represented in figure $2 B$ ) $(n=10): 1)$ when the deep side of the graft was placed against the deep side of the host blastoderm (figure $6 A$ ) and cultured for 1 day, a round mass becomes obvious at the place of grafting (figure $6 B$ ); an induced secundary primitive streak was never seen at the grafting region; in sections, no reaction of the chicken UL was observed; 2) when the superficial part of the UL of the quail graft was placed against the deep side of the chicken host, only a vesicle formed by quail cells developed but no secundary PS. In both cases a normal primary PS developed (figure $6 B$ ) under influence of the autochthonous chicken Rauber's sickle.

After placing a fragment of quail Rauber's sickle on the central part of the cranial quadrant of an unincubated chicken blastoderm (as represented in figure $2 C$ ) ( $n$ $=5$ ): figure $7 A$ shows the place of a voluminous quail Rauber's sickle at the start of the culture. After $4 \mathrm{~h}$ of culture, the Rauber's sickle material has largely spread over the implantation region (figure $7 B$ ) and is only visible as a dark area. After approximately 1 day of culture it was seen that two embryos had developed in the area centralis: one, the primary embryo developed under influence of the original chicken Rauber's sickle and the secundary embryo induced under the influence of the quail Rauber's sickle (figure $7 \mathrm{C}$ ). Sometimes, as is the case of the chimera of figure $7 C$, the induced embryo grows faster then the primary embryo. Perhaps this can be explained by the larger and more concentrated quantity of Rauber's sickle material. In every chimera where a quail Rauber's sickle was placed, a secundary embryo developed. If the quail Rauber's sickle was involuntary placed on the caudal half of the chicken blastoderm sometimes it was partially taken up by the primary embryo. On sections we see the typical flat sickle endoblast cells derived from the quail Rauber's sickle [9] below the primitive streak. 

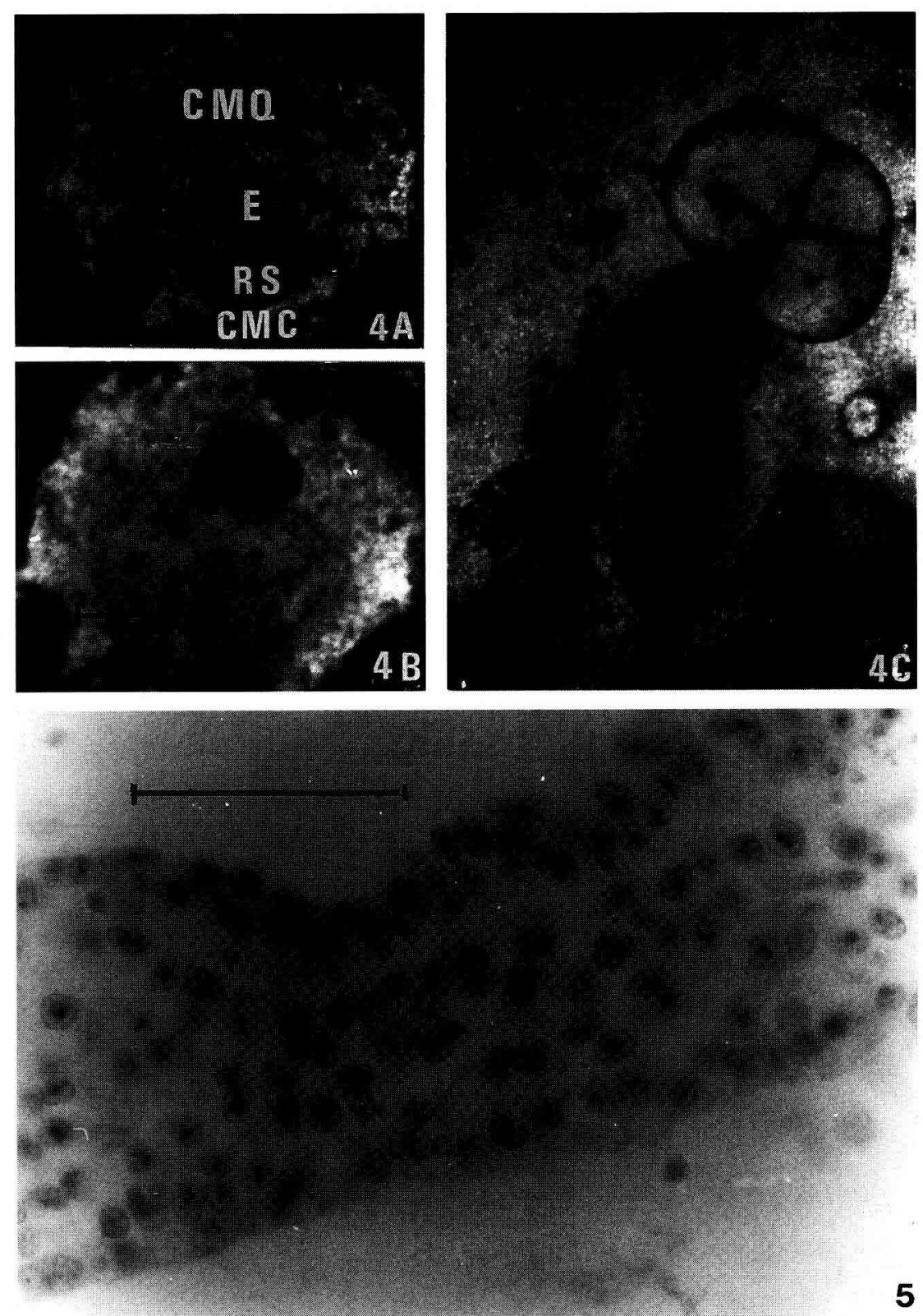

Figure 4. A) Unincubated chicken blastoderm with a large fragment of caudal marginal zone (CMQ) from an unincubated quail blastoderm placed on the cranial quadrant region, at the start of the culture; upper layer of quail graft faces the deep layer of the chicken blastoderm; E: fenestrated endophyll; RS: Rauber's sickle and CMC: caudal marginal zone of chicken blastoderm; bar: $1 \mathrm{~mm}$. B) The same chimera as in A, after $6 \mathrm{~h}$ of in vitro culture; the quail graft indicated by an arrowhead has taken a round aspect; bar: $1 \mathrm{~mm}$. C) The same chimera as in A and B after $23 \mathrm{~h}$ culture. At the place of the graft a 
After culture of an isolated central UL disc (without deep layer) excised from a prestreak chicken blastoderm (approximately stage XIII of Eyal-Giladi and Kochav [18]), no PS developed $(n=5)$. Only a vesicle formed. This is in agreement with the observations of Azar and Eyal-Giladi [1].

After placing a quail Rauber's sickle fragment on the ventral side of a central UL disc of a similar prestreak chicken blastoderm, from which the deep layer was removed (figure $8 A$ ), no primitive streak developed after 1 day of culture (figure $8 B)(n=5)$. The UL formed a vesicle in which sometimes the nearly unchanged Rauber's sickle fragment was still visible by transparence. Thus, spreading of the sickle material did not occur here. If a Rauber's sickle fragment with an associated sheet of endophyll was placed on the deep layer-free central $\mathrm{UL}$ disc, as represented in figure $2 D$ (figure $9 A)$, also no PS developed (figure $9 B)(n=5)$ (confirmed by observations on the sections).

\section{DISCUSSION}

Not withstanding the existence of many (however not always morphologically specific) staining methods used for molecular
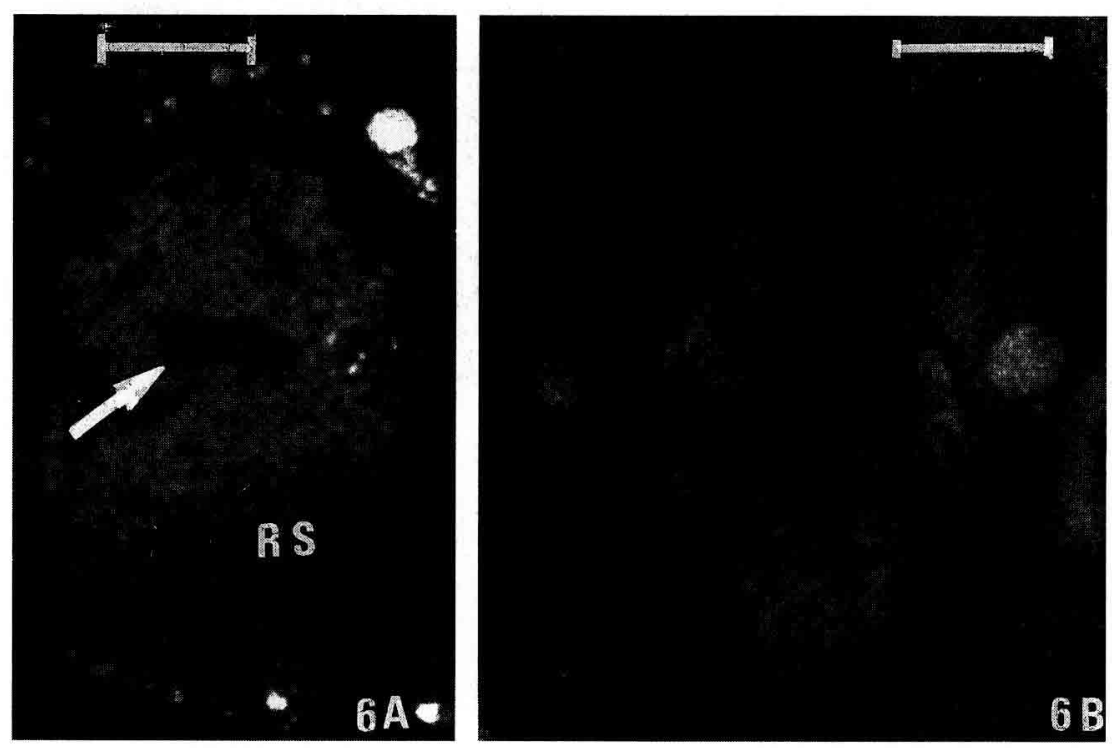

Figure 6. A) Unincubated chicken blastoderm with a fragment of UL (indicated by arrow), removed from above the Rauber's sickle of an unincubated quail blastoderm (deep side against deep side), at the start of the culture; RS: Rauber's sickle of the chicken blastoderm; bar: $1 \mathrm{~mm}$. B) The same chimera after 1 day of culture: a round mass is visible at the place of the grafting; no secundary induced PS appears. Only a primary PS is visible; bar: $1 \mathrm{~mm}$.

voluminous vesicle has formed. Only a primary embryo has developed normally, starting from the autochthonous Rauber's sickle region; bar: $1 \mathrm{~mm}$.

Figure 5. Section through the region of a graft after $23 \mathrm{~h}$ of culture, when the deep layer of a caudal marginal zone of an unincubated quail blastoderm was placed on the deep side of an unincubated chicken blastoderm (cranial quadrant region); both the upper layer (ULQ) and the deep part of the quail marginal zone (Q) are visible above the chicken upper layer (UL CH): no thickening of the latter and no other induction phenomena are visible; bar: $50 \mu \mathrm{m}$. 

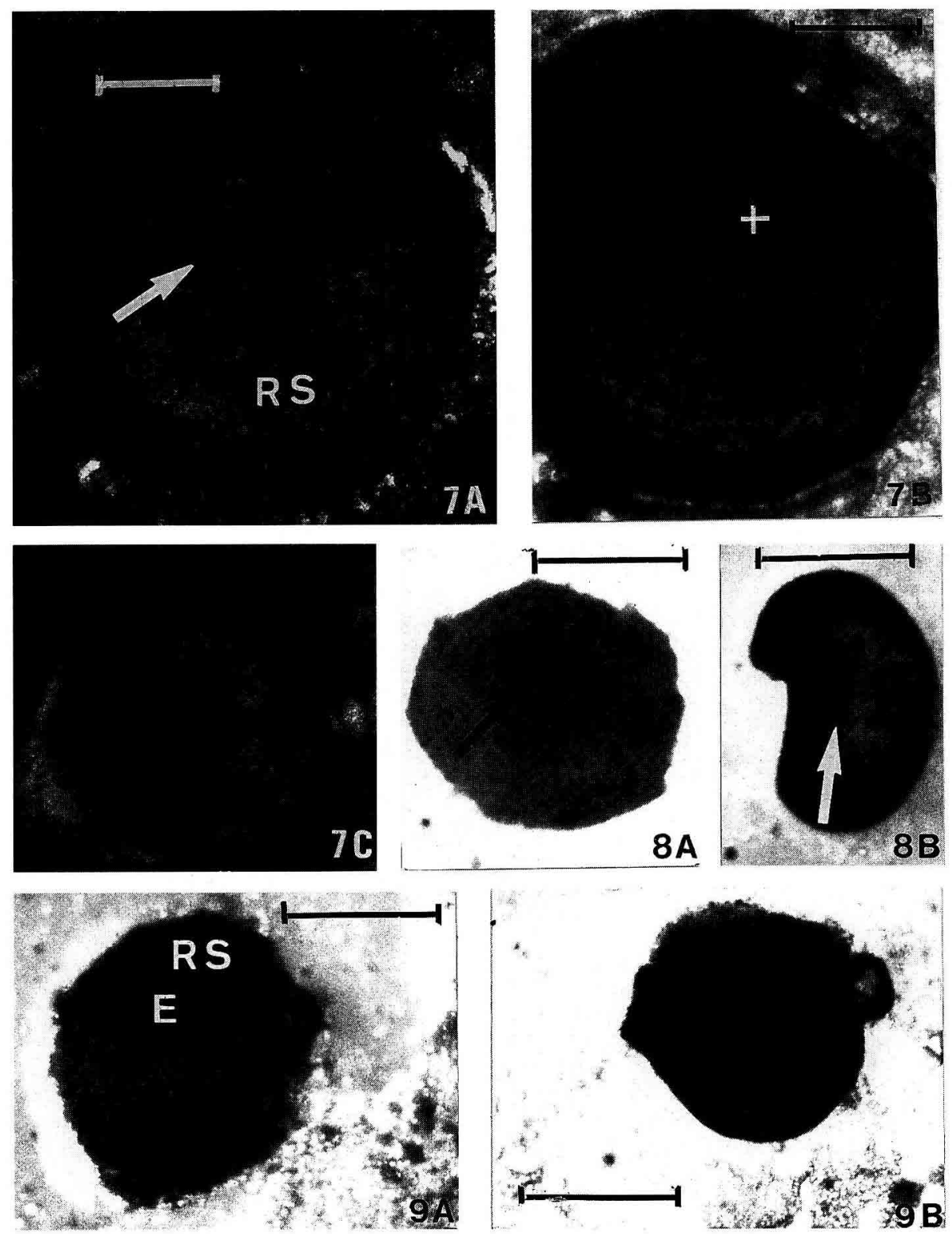

Figure 7. A) Unincubated chicken blastoderm on which a fragment of Rauber's sickle (indicated by arrow) from unincubated quail was placed at the start of the culture; RS: Rauber's sickle from the unincubated chicken blastoderm with behind it the chicken caudal marginal zone (CMC); bar: $1 \mathrm{~mm}$. B) The same chimera as in A, after $4 \mathrm{~h}$ of culture; spreading of the quail Rauber's sickle material forming a dark zone (+) on the deep side of the chicken blastoderm is obvious; bar: $1 \mathrm{~mm}$. C) Area pellucida of the same chimera as represented on A and B after $23 \mathrm{~h}$ of culture and fixation: two embryos are visible, the primary embryo (I) is somewhat curved and is smaller than the induced secundary embryo (II); bar: $1 \mathrm{~mm}$. 
biology studies, the most elementary components or cell groups of the avian unincubated blastoderm and their functional interactions are often ignored or erroneously described or defined. For instance, Stern [39] claims that "Koller's sickle (Rauber's sickle) is a part of the superficial portion of the marginal zone at its posterior extremity". We on the contrary have shown that Rauber's sickle is a deep component localized cranially to the caudal marginal zone [9] (figure 10). Moreover in the present study we clearly demonstrate that Rauber's sickle is clearly functionally different from its sur- rounding cell groups, i.e. the caudal marginal zone cells and the UL above Rauber's sickle.

After in situ injection of DiI in a group of $20-100$ cells at the midline of Rauber's sickle of unincubated blastoderms, followed by further incubation, Izpisua-Belmonte et al. [23] found DiI-labelled cells in the region of Hensen's node. According to the same authors this would demonstrate that Rauber's sickle cells are precursors of some Hensen's node cells and are thus contributing to intra-embryonic tissues (the main body axis and its derivatives). In contrast, in

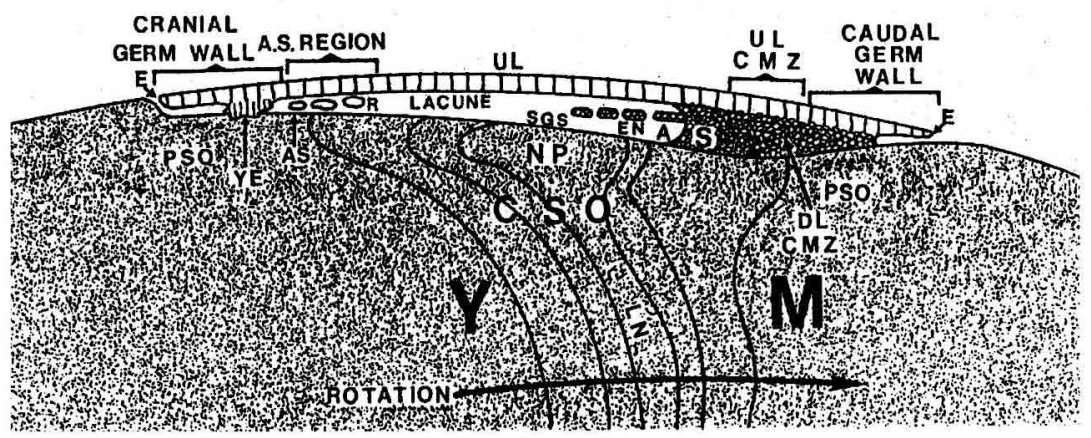

Figure 10. Schematic representation of a mediosagittal section through an unincubated quail blastoderm with surrounding ooplasms after fixation in situ on the egg yolk ball. UL: upper layer; EN: incomplete endophyll; S: Rauber's sickle; UL CMZ: upper layer from the caudal marginal zone; DL CMZ: deep part of the caudal marginal zone; the caudal marginal zone being a more or less transparent part behind Rauber's sickle, adherent to the caudal peripheral subgerminal ooplasm (PSO); SGS: subgerminal space forming a caudal pocket $A$ (axilla shaped) and cranial recess $\mathrm{R}$ in which free yolk masses or sometimes cells are found forming the anti-sickle (AS); E: edge of the blastoderm; YE: early development of the yolk endoblast, growing into the peripheral subgerminal ooplasm (PSO); YM: the voluminous yolk mass of the egg yolk ball in which the eccentricity of the successive yolk layers is represented; CSO: central subgerminal ooplasm in which the boot-shaped central nucleus of Pander (NP) is seen; Also boot-shaped surrounding yolk layers as a result of the rotation in utero (arrow indicates direction of rotation and compression of the yolk mass under influence of gravity and egg rotation) $[3,5-7]$; LN: bended latebra neck.

Figure 8. A) Central UL disc (without deep layer) excised from a prestreak chicken blastoderm (approximately stage XIII of Eyal-Giladi and Kochav [18]) on which a Rauber's sickle fragment (indicated by arrow) of unincubated quail blastoderm was placed, at the start of the culture; bar: $1 \mathrm{~mm}$. B) The same chimera of A after $20 \mathrm{~h}$ culture: the Rauber's sickle fragment (indicated by arrow) is still visible without spreading (confirmed on sectioned material): no PS has formed; bar: $1 \mathrm{~mm}$.

Figure 9. A) Central UL disc (without deep layer) excised from a prestreak chicken blastoderm (Stage XIII of Eyal-Giladi and Kochav [18]) on which a Rauber's sickle fragment (RS) with associated part of endophyll sheet (E) of unincubated quail blastoderm has been placed, at the start of the culture; bar: $1 \mathrm{~mm}$. B) The same chimera as of A, after $18 \mathrm{~h}$ culture; no PS is visible; bar: $1 \mathrm{~mm}$. 
all our transplantation studies with quail Rauber's sickle fragments placed on unincubated chicken blastoderms $[9,11,13,14]$ we never found quail cells in the later developed embryonic germ layers (which are found to be entirely formed by chicken cells). This indicates that Rauber's sickle is and remains an extra-embryonic structure with only temporarily inducing properties and thus behaves like the Nieuwkoop centre of amphibian blastulas. Thus, we can not agree with the above-mentioned conclusions of Izpisua-Belmonte et al. [23]. We think that by trying to inject a small group of loosely bound Rauber's sickle cells with DiI, labelling of the neighbouring upper layer cells also occurred. The latter of course will form part of the definitive embryonic tissues.

According to Eyal-Giladi et al. [21], the marginal zone is only composed of a single layer in continuity with the more cranial upper layer. By contrast earlier observations and our present histological study of the germ disc of unincubated quail eggs indicate that the caudal marginal zone is composed of two parts: 1) an upper layer part, in continuity with the more cranial upper layer above Rauber's sickle; 2 ) a deep part, localized behind Rauber's sickle and in intimate contact with the peripheral subgerminal ooplasm. During the preparation of the unincubated blastoderm for in vitro culture, the latter deep part of the marginal zone appears as transparent (figure 4A) or non-existent by contrast to the denser Rauber's sickle. That it is still present during our in vitro culture is visible on the sections after placing a quail caudal marginal zone on a chicken blastoderm (see figure 5). In figure 10, the relationship of the different components in the germ disc of unincubated quail eggs is represented, according to our most recent observations.

From the depth to the surface, there are components of the egg which successively have influenced, influence or will influence the general basic development of the avian embryos. The deeper yolk mass under the combined influence of gravity and rotation in utero of the egg shell is no longer radially symmetric but presents a bending of the successive yolk layers surrounding the nucleus of Pander [33], which remains visible after laying $[3,8]$. Under the influence of the same forces the cranial subgerminal ooplasm loses contact but the caudal subgerminal ooplasm remains in contact with the blastoderm via Rauber's sickle and the deep part of the caudal marginal zone [7, 8]. During incubation the extra-embryonic part of the blastoderm (Rauber's sickle and endophyll) will have an inducing influence on the superficial UL from which all the embryonic tissues will develop.

Previous quail-chicken exchange experiments of small pieces of the caudal marginal zone of unincubated blastoderms (peripheral to Rauber's sickle) have shown that the caudal marginal zone is not involved in gastrulation movements [12]. We have also shown that in the total absence of the caudal marginal zone (already during the unincubated stage), normal neurogastrulation phenomena still occur [13]. Moreover, after isotopically exchanging the Rauber's sickle in an unincubated chicken blastoderm by a quail Rauber's sickle, and in vitro culture, we observed that the sickle endoblast and junctional endoblast were only formed by quail cells [14]. This also indicates that there is no movement of caudal marginal zone cells into the sickle endoblast via Rauber's sickle, as has been claimed by Eyal-Giladi and Khaner [19] and by Eyal-Giladi et al. [20]. The latter study was performed by labelling the caudal marginal zone (without Rauber's sickle included), with the fluorescent dye rhodamine-dextran-lysine at the chicken XI stage $[18,26]$. This stage corresponds approximately with our unincubated blastoderms. According to our interpretation, by this labelling method Eyal-Giladi et al. [20], just seem to demonstrate our conclusion that the caudal marginal zone cells remain essentially in situ (taking into account a possible slight leaking of the dye) 
during gastrulation. In another study, EyalGiladi et al. [21] placed caudal marginal zones of stage $X$ chicken blastoderms on the ventral side of stage XIII upper layer central discs from which the deep layer (endophyll included) was peeled off: no induction of a primitive streak could be obtained. The latter authors explain these observation by assuming that caudal marginal zone cells must first migrate via Rauber's sickle into the developing hypoblast (deep layer) before they can induce a PS.

Besides the 'generation gap' between 'the young' Rauber's sickle and the much 'older' central disc, we on the contrary have a more simple explanation for their results: the Anlage fields of a UL central disc of a stage XIII blastoderm are already determined. Indeed, we have shown that the determination of the tissues in the UL begins after 5-6 $\mathrm{h}$ of incubation [12]. In the present study, the chicken blastoderms (stage XIII) that we have used have been incubated for 8-10 h. So determination must already have taken place. Also the study of Khaner [25] supports this explanation.

Even in the presence of endophyll in the unincubated chicken blastoderms in our study (experimental procedure represented in figure $2 A, B$ ), no secundary PS developed either under the influence of the caudal marginal zone (which also contains a deep portion but no Rauber's sickle material), or under the influence of the upper layer removed from above Rauber's sickle. Fragments of upper layer taken from above Rauber's sickle do not induce and do not differentiate when placed on unincubated blastoderms. This also suggests that Rauber's sickle which belongs to the deep vegetal extraembryonic part of the blastoderm [6] is not formed from upper layer material migrating from the surface into the depth as thought by Vakaet [42]. The formation of erythrocytes seems to be an important function of the caudal marginal zone [36]. According to Zagris [44] the marginal zone of unincubated chick blastoderms is the contributor of prospective erythroid cells. This erythroid cell determination and differentiation was observed in culture in the absence of gastrulation movements and PS formation. In the unincubated chicken blastoderm, the homeobox containing gene goosecoid (gsc) (which provides a temporary marker for the organizer region), is in the unincubated chicken blastoderm only expressed at the level of Rauber's sickle and not in the caudal marginal zone [23]. Later, at stage XII [18], staining is also clearly seen in the migrating sickle endoblast but never in the caudal marginal zone behind Rauber's sickle. The whole-mount in situ hybrization technique thus gives results in favour of our conclusion that only Rauber's sickle and not the caudal marginal zone plays a role as early gastrulation organizer. Our earlier observations (by trypan blue or radioactive labelling of the ooplasmic layers) indicating that Rauber's sickle is the most stable part of the unincubated or early incubated blastoderm $[4,8]$, and that Rauber's sickle during incubation transforms mainly in the massive $\mathrm{V}$ shaped junctional endoblast which remains localized in situ on its subgerminal ooplasm [9], are also not in favour of the hypothesis of Eyal-Giladi et al. [20], that caudal marginal zone cells migrate cranially via Rauber's sickle.

Chick Vg1 is a member of the TGF $\beta$ family of signalling molecules whose homologue in Xenopus is implicated in mesoderm induction [37]. The latter authors found expression of chick Vg1 in the UL region above Rauber's sickle and above the cranially growing sickle endoblast (what they call the "marginal zone of the area pellucida"). This seems to indicate that the sickle endoblast and the Rauber's sickle from which it is derived [9], influence the overlying UL to express the chick Vgl.

\section{ACKNOWLEDGEMENTS}

The authors wish to thank Mrs V. Van der Stock for skillful technical assistance, Mr F. De Bruyn for photography and artwork, and Miss $V$. De Maere for typing the manuscript. 


\section{REFERENCES}

[1] Azar Y., Eyal-Giladi H., Marginal zone cells: the primitive streak-inducing component of the primitive hypoblast in the chick, J. Embryol. Exp. Morph. 52 (1979) 79-88.

[2] Callebaut M., Extracorporal development of quail oocytes, Experientia 24 (1968) 1242-1243.

[3] Callebaut M., The constituent oocytal layers of the avian germ and the origin of the primordial germ cell yolk, Arch. Anat. Microsci. 72 (1983) 199-214.

[4] Callebaut M., Ooplasmic localization and segregation in avian blastoderms: fate of the four ooplasms, Arch. Biol. 98 (1987) 441-473.

[5] Callebaut M., Early eccentricity in gravitationally oriented quail germs, Eur. J. Morph. 31 (1993) 5-8.

[6] Callebaut M., Unequal caudo-cephalic ooplasmic uptake and eccentric formation of the subgerminal space below unincubated quail blastoderms presenting a Koller's sickle, Belg. J. Zool. 123 (1993) 107-112.

[7] Callebaut M., Development of quail germs during and after gravitationally oriented bilateral symmetrization, Eur. Arch. Biol. 104 (1993) 135-140.

[8] Callebaut M., Relationship between the avian blastoderm and the subgerminal ooplasm, Eur. Arch. Biol. 105 (1994) 111-123.

[9] Callebaut M., Van Nueten E., Rauber's (Koller's) sickle: the early gastrulation organizer of the avian blastoderm, Eur. J. Morph. 32 (1994) 35-48.

[10] Callebaut M., Van Nueten E., Gastrulation inducing potencies of endophyll and Rauber's sickle in isolated caudocranially oriented prestreak avian blastoderm quadrants (or fragments) in vitro, Eur. J. Morph. 33 (1995) 221-235.

[11] Callebaut M., Van Nueten E., Ectopic endophyll induces a neural plate or a miniature embryo in the caudal marginal zone and Siamese twins in the area centralis, Biol. Jb. Dodonaea 64 (1996) 39-63.

[12] Callebaut M., Van Nueten E., Bortier H., Harrisson F., Van Nassauw L., Map of the Anlage fields in the avian unincubated blastoderm, Eur. J. Morph. 34 (1996) 347-361.

[13] Callebaut M., Van Nueten E., Harrisson F., Van Nassauw L., Schrevens A., Bortier H., Avian gastrulation and neurulation are not impaired by the removal of the marginal zone at the unincubated blastoderm stage, Eur. J. Morph. 35 (1997) 69-77.

[14] Callebaut M., Van Nueten E., Bortier H., Harrisson F., Van Nassauw L., Schrevens A., Spatial relationship between endophyll, primordial germ cells sickle endoblast and upper layer in cultured avian blastoderms, Reprod. Nutr. Dev. 37 (1997) 293-304.
[15] Callebaut M., Van Nueten E., Harrisson F., Van Nassauw L., Schrevens A., Induction of (pre)gastrulation and or (pre)neurulation by subgerminal ooplasm and Rauber's sickle in cultured anti-sickle regions of avian unincubated blastoderms, Eur. J. Morph. 36 (1) (1998) $1-10$.

[16] Demalsy P., Callebaut M., Plain water as a rinsing agent preferable to sulfurous acid after the Feulgen nuclear reaction, Stain. Technol. 42 (1967) 133-136.

[17] Eyal-Giladi H., The early embryonic development of the chick as an epigenetic process, Crit. Rev. Poultry Biol. 3 (1991) 143-166.

[18] Eyal-Giladi H., Kochav S., From cleavage to primitive streak formation: a complementary normal table and a new look at the first stages of development of the chick I. General morphology, Dev. Biol. 49 (1976) 321-337.

[19] Eyal-Giladi H., Khaner O., The chick's marginal zone and primitive streak formation II. Quantification of the MZ's potencies-temporal and spatial aspects, Dev. Biol. 134 (1989) 215-221.

[20] Eyal-Giladi H., Debby A., Harel N., The posterior section of the chick's area pellucida and its involvement in hypoblast and primitive streak formation, Development 116 (1992) 819-830.

[21] Eyal-Giladi H., Lotan T., Levin T., Avner O., Hochman J., Avian marginal zone cells function as primitive streak inducers only after their migration into the hypoblast, Development 120 (1994) 2501-2509.

[22] Gaillard P., Germinal or covering epithelium, Natuurwetensch Tijdschr (Gent) 3 de BelgNederl Cyto-embryol Dagen, 1949, pp. 5-8.

[23] Izpisua-Belmonte J., De Robertis E., Storey K., Stern C., The homeobox gene goosecoid and the origin of the organizer cells in the early chick blastoderm, Cell 74 (1993) 645-659.

[24] Khaner O., Axis determination in the avian embryo, Curr. Top. Dev. Biol. 28 (1993) 155-179.

[25] Khaner O., The rotated hypoblast of the chicken embryo does not initiate an ectopic axis in the epiblast, Proc. Nat. Acad. Sci. 92 (1995) 10733-10737.

[26] Kochav S., Ginsburg M., Eyal-Giladi H., From cleavage to primitive streak formation: A complementary normal table and a new look at the first stages of the chick II. Microscopic anatomy and cell population dynamics, Dev. Biol. 79 (1980) 296-308

[27] Koller C., Untersuchungen über die Blätterbildung im Hühnerkeim, Arch. Mikrosk. Anat. 20 (1882) 171-211.

[28] Koshida Y., Kosin I.L., Intranuclear sex dimorphism in the feathers of six species of galliformes, Cytologia (Tokyo) 33 (1968) 230-240. 
[29] Le Douarin N., Barq G., Sur l'utilisation des cellules de la caille japonaise comme marqueurs biologiques en embryologie expérimentale, C.R. Acad. Sci. Paris 269n (1969) 1543-1546.

[30] New D.A.T., A new technique for the cultivation of the chick embryo, J. Embryol. Exp. Morph. 3 (1955) 326-331.

[31] Nieuwkoop P.D., The formation of the mesoderm in urodelean amphibians I. Induction by the endoderm, Roux. Arch. Dev. Biol. 162 (1969) 341-373.

[32] Nieuwkoop P.D., The organization center of the amphibian embryo: its spatial organization and morphogenetic action, Adv. Morphogen. 10 (1973) 1-39.

[33] Pander C., Historiam metamorphoseos quam ovum incubatum prioribus quinque diebus subit, FE Nitribitt Wirceburgi, 1817

[34] Rauber A., Über der Stellung des Hühnchens in Entwicklungsplan, W. Engelsman, Leipzig, Germany, 1876.

[35] Romeis W., Mikroskopische Technik 15 Aufl, Leibnitz, München, Germany, 1948.

[36] Settle G., Localization of the erythrocyte forming areas in the early chick blastoderm cultivated in vitro, Contrib. Embryol. 241, Carnegie Institution of Washington, Washington DC, 1954, pp. 223-237.

[37] Shah S.B., Skromne I., Hume C., Kessler D., Lee K.J., Stern C.D., Dodd J., Misexpression of chick $\mathrm{Vgl}$ in the marginal zone induces primitive streak formation, Development 124 (1997) 5127-5138.

[38] Spratt N.T., Haas H., Integration mechanisms in development of the early chick blastoderm II. Role of morphogenetic movements and regenerative growth in synthetic and topographically disarranged blastoderms, J. Exp. Zool. 147 (1961) 57-94.

[39] Stern C., The marginal zone and its contribution to the hypoblast and primitive streak of the chick embryo, Development 109 (1990) 667-682

[40] Vakaet L., Morphologische en experimentele studie over de pregastrulatie en gastrulatie der vogelkiem, thesis, Arscia, Brussels, Belgium, 1962.

[41] Vakaet L., Some new data concerning the formation of the definitive endoblast in the chick embryo, J. Embryol. Exp. Morp. 10 (1962) 38-57.

[42] Vakaet L., Cinephotomicrographic investigation of gastrulation in the chick blastoderm, Arch. Biol. (Liège) 81 (1970) 387-426.

[43] Waddington, Experiments on the development of chick and duck embryos, cultivated in vitro, Philos. Trans. Roy. Soc. B 221 (1932) 179-230.

[44] Zagris N., Determination of Erythroid cells in unincubated chick blastoderms, Dev. Growth Differentiation 27 (1985) 95-100. 